\title{
Т.С. Кенешов
}

КГУСТА им. Н. Исанова, Бишкек, Кыргызская Республика

\author{
T.S. Keneshov
}

KSUCTA n.a. N.Isanov, Bishkek, Kyrgyz Republic

t.keneshov@mail.ru

\section{КОНЦЕПЦИЯ РАЗВИТИЯ МАЛЫХ И СРЕДНИХ ГОРОДОВ КЫРГЫЗСТАНА}

\section{CONCEPT OF DEVELOPMENT OF SMALL AND MEDIUM CITIES OF KYRGYZSTAN}

\begin{abstract}
Бул макалада "айыл" категориясынан "шаар" категориясына өткөрУҮ менен өлкөдө кичи шаарлардын санын көбөйтүY мүмкүндүгүн жана урбанизациянын дензгээлин жогорулатуунун материалдары көрсөтүлгөн. Шаарлардын шаар курулуштук өнүгүҮ, алардын башкы пландарын иштеп чыгуу, өлкөнү өнүктүрҮҮ, өнөр жай жана өлкө боюнча урбанизациянын деңгээлин жогорулатуу көйгөйлөрүн баяндайт.
\end{abstract}

өзөк сөздөр: демографиянын өсүшү, аймактык өнүгүҮ, шаарларды өнүктүрүҮ, өсүУ чекиттери, өлкөнүн келечектеги өнүгүшү, урбанизациянын деңзээли, жалпы план.

В статье представлено материаль по уровню урбанизации и возможность через увеличение количества мальх городов республики из категории «села» в категорию «города». Описаны проблемы градостроительного развития существующих городов, разработка генеральных планов и планов развития страны, промышленности и повышение уровня урбанизации по всей территории республики.

Ключевые слова: демографический рост, развитие регионов, развитие городов, точки роста, перспективное развитие республики, уровень урбанизачии, генеральньий план.

The article presents the rationale for increasing the level of urbanization by increasing the number of small and medium-sized cities of the republic through the transfer of large and large villages from the category of "village" to the category of "city". The problems of urban development of existing cities, the development of master plans and plans for the development of the country, industry and increasing the level of urbanization throughout the country are described.

Key words: demographic growth, regional development, urban development, growth points, perspective development of the republic, level of urbanization, master plan

В настоящее время, по Статистическим данным, численность населения Кыргызстана насчитывает 6 млн. 389 тысяч жителей, при этом начиная с 2011 года ежегодный прирост населения составляет более 100 тысяч граждан. При этом, на начало 2017 г., около 65\% населения от общей численности населения, страны находится в возрасте от одного года до 40 лет. Такое сложившееся демографическое состояние с наличием большего количества молодого и трудоспособного населения в республике, является главным показателем уровня урбанизации.

Сложившаяся прогрессирующая демографическая ситуация для всех стран мира, в том числе для Кыргызской Республики, является очень важным исходным фактором и определенным залогом для активной организации деятельности государственных органов, и лучшим условием в обеспечении устойчивого перспективного развития страны. Демографические показатели в республике непосредственно взаимосвязаны 
функционированием и развитием городов и населенных пунктов. Несмотря на активную миграцию трудоспособного населения Кыргызстана за границу наблюдается рост численности жителей в населенных пунктах и городах.

В настоящее время, на территории Кыргызской Республики 7 областей, 2 города республиканского подчинения, 40 административных районов, 453 айылных (сельских) аймаков и 31 город, включая города республиканского назначения - города Бишкек и Ош. Общее количество населенных пунктов в стране составляет всего 1942 единиц, из них 46 населенных пунктов находятся в составе существующих городов. [6]

Президентом КР С.Ш. Жээнбековым 2018 и 2019 года объявлены Годом развития регионов. Этому предшествовала принятое Правительством КР «Концепция региональной политики на период 2018-2022 годов» (Постановление Правительства Кыргызской Республики от 31 марта 2017 года №194 «Об утверждении Концепции региональной политики Кыргызской Республики на период 2018-2022 годов»). Где, 18 городов определены "точками роста" которые выполняют функции административных центров - городов республики, областей и районов. Из них 11 городов являются промышленными городами и выполняют функции мест приложения труда, культурно-бытового обслуживания, транспорта и межселенного обслуживания и т.п. [7]. Для реализации «Концепции» должны требуется разработка генеральных планов «городов - точек роста». Однако, несмотря на активную информацию, в средствах массовой информации, даже основополагающие начальные работы до настоящего времени не начаты. Например, разработка генпланов городов и других важных проектов, из-за несвоевременной разработки, «Концепция» может остаться не выполненной, также срываются «гарантированные государственные минимальные социальные обещания» перед населением.

Исходя из выше изложенного следует обратить внимание на то, что в настоящее время в более 40 населенных пунктах Кыргызстана, количество проживающих людей перевалило за 10000 и более человек в каждом из них (см.таблицу 1.). Согласно законам КР «Об административно-территориальном устройстве КР», «О градостроительстве и архитектуре КР» и других нормативно-правовых актов, населенные пункты, согласно приложенному списку, возможно перевести в категорию городов. Все они официально имеют статус «сёл», из них 18 сел являются центрами административных районов, и состоят они, как правило, из нескольких айылных окмотов, во многих случаях из слитых айылных аймаков, но механически разделены в виде отдельных территориально-административных единиц. Перевод таких сел в категорию городов позволило бы сократить количество айылных окмотов (возможно и айылных аймаков) и тем самым сэкономить бюджетные финансовые средства на содержание аппарата и связанных с ним других затрат. И в этом случае, общее число городского населения в республике увеличится на $50 \%$ от общей численности населения, что будет благоприятствовать повышению уровня урбанизации в стране, который в свою очередь будет способствовать развитию уровня образования, культуры, социально-коммунального обслуживания населения в условиях интенсивного развития научно-технического прогресса $[2,3,4]$.

Таблица 1 - Список населенных пунктов Кыргызстана с численностью жителей на 01.01.2019 года. (по данным Нацстаткома КР) [9]

\begin{tabular}{|l|l|c|c|}
\hline $\begin{array}{c}\text { № } \\
\text { п/п }\end{array}$ & $\begin{array}{c}\text { Наименование области, районов айылного } \\
\text { аймака и населенного пункта }\end{array}$ & $\begin{array}{c}\text { Численность } \\
\text { постоянного поселения }\end{array}$ & Примечание \\
\hline & \multicolumn{1}{|c|}{ Ошская область } \\
\hline 1 & с. Гюльбахор & 10115 & \\
\hline 2 & с. Джаны-Кыштак & 10320 & \\
\hline 3 & с. им.Чапаева & 10343 & \\
\hline 4 & с. Кара-Таш & 10483 & \\
\hline 5 & с. Араван & 10724 & \\
\hline
\end{tabular}




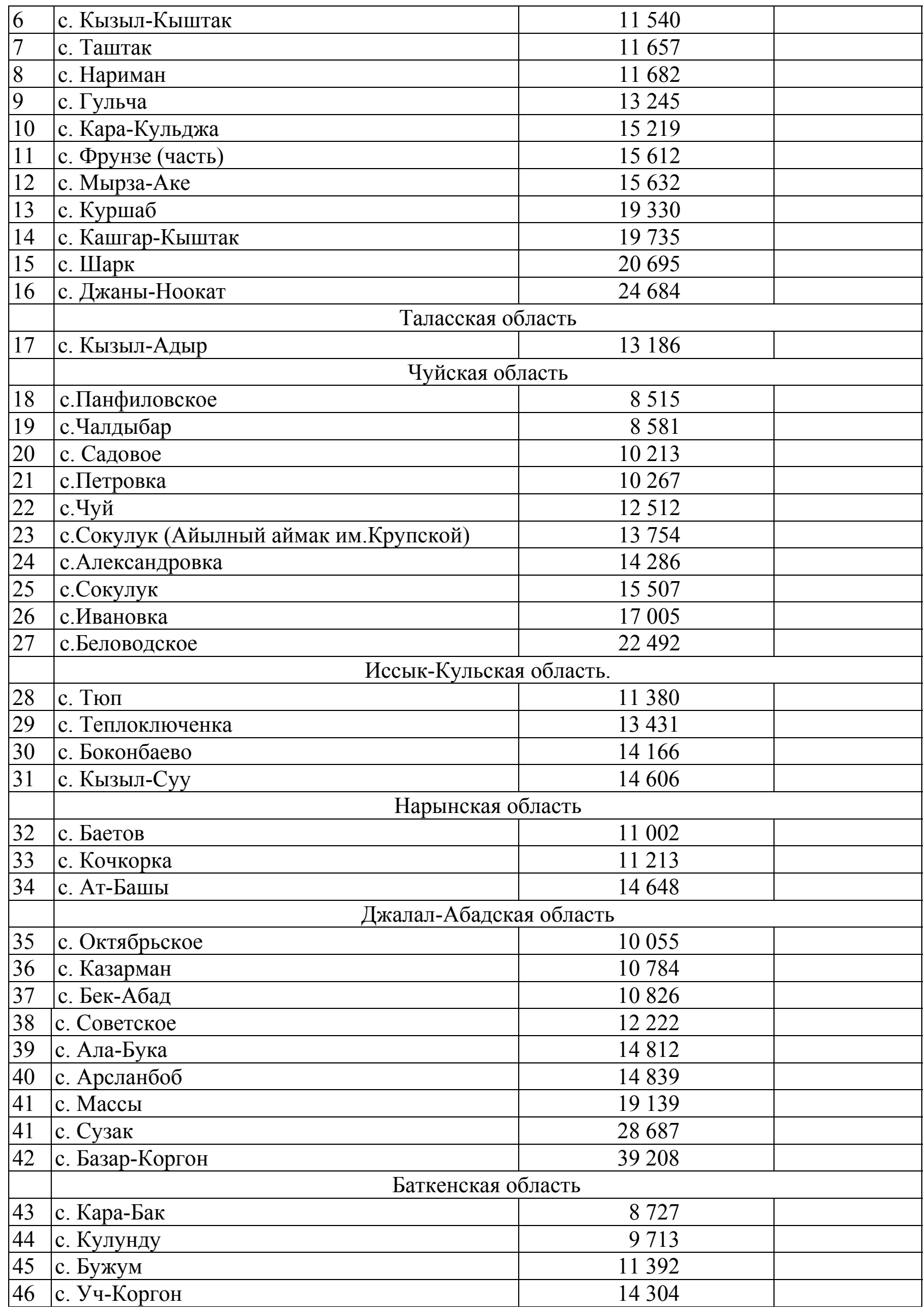


Это позволит упорядочить и решить административно-территориальные, земельные и правовые вопросы в указанных «новых городах» с определением их новых административных границ. Из-за несвоевременного решения новых административно территориальных границ, например, не смотря на наличие соответствующих Постановлений Правительства КР «О разработке и утверждение новых административно-территориальных границ» по г. Бишкек (2006), г. Чолпон-Ата (2007) и г. Ош (2016) до настоящего времени не решены. Из-за этого часто возникают земельные и градостроительные правонарушения, которые приводят, во многих случаях, к конфликтным ситуациям и судебным разбирательствам [5].

Для решения накопившихся проблем до настоящего времени в городах и населенных пунктах принята Правительством специальная "Программа по разработке генеральных планов до 2025 года". Где в соответствии с "Программой Правительства Кыргызской Республики по разработке генеральных планов, населенных пунктов Кыргызской Республики на 2018-2025 годы" утвержденной постановлением Правительства от 17 августа 2017 года №490 необходимо разработать генеральные планы всех городов и ПГТ (поселков городского типа), 25 сел - районных центров и 241 приграничного села в первую очередь и другие населенные пункты до конца указанного срока [7].

При условии выполнения соответствующего решения по приданию статуса городам появляются следующие положительные предпосылки:

1. Организация и обеспечение системного управления и регулирования городами вновь организованными Мэриями;

2. Экономия государственных бюджетных средств за счёт уменьшение количества аппаратов айыльных окмотов и аймаков;

3. Расширение территорий городов для размещения и развития промышленных, коммунальных, социально-культурных объектов и других необходимых объектов для жизнедеятельности граждан;

4. Коренное улучшение обслуживания населения государственными, социально культурными, коммунальными и общественными организациями и учреждениями;

5. Организация предприятий логистических центров, технопарков, кампусов за счет строительства новых и переоборудования существующих складов, колхозных токов, бывших зданий сельхозтехники, автобаз, коммунальных и других территорий;

6. В определении и утверждении новых административно-территориальных границ городов с расширением территорий для жилищного и другого строительства с учетом перспектив их развития;

7. Упорядочение и улучшение облика застройки городов, повышение эффективности и рационального использования ранее неиспользуемых территорий, введения надлежащего контроля и надзора за строительством объектов и рациональным использованием земель;

8. Ведение новой экономической оценки городских земель, недвижимости, развитие инженерно-коммунальной инфраструктуры, дорожно-транспортной системы, парков, площадей, тротуаров и др;

9. Появление возможности повышения самосознания и оценки жителями значения городской социально-культурной, образовательной и других возможностей, и в целом создания необходимых городских условий для повышения культурного уровня населения и материальной базы для соответствующего воспитания подрастающего поколения.

Отрицательной стороной при отнесении предложенных сел к категории городов может быть:

1. Нарушение сложившейся системы айыльных аймаков и окмотов, и порядок в обслуживании социально-бытовыми вопросами и оказания других услуг жителей айылными окмотами; 
2. Частичное лишение статуса сельского жителя, сложившегося профиля развития сельского населенного пункта и монофункциональность крупных населенных пунктов;

3. В связи с переименованием населенного пункта подлежат к изменению фирменные бланки, печати, штампы учреждений, организаций, предприятий и других субъектов;

4. Замена паспортов граждан, удостоверения работающих сотрудников, а также другие необходимые документы для недвижимого и движимого имущества независимо от вида собственности;

5. Нарушаются сложившиеся границы и территории избирательных участков, организованные по субъективным критериям.

Проведение такого мероприятия в виде комплексных работ в Кыргызской Республике позволит поднять международный рейтинг и уровень урбанизации Кыргызстана на основе имеющихся объективных предпосылок, а также позволит выполнение Рекомендаций и «Целей» принятой Программы на Всемирной Конференции ООН по устойчивому развитию страны и городов Хабитат-III в г.Кито, Республика Найроби, в 2016 году [1].

\section{Список литературы}

1. Городское планирование для руководителей городов ООН-ХАБИТАТ/ за лучшее будущее городов / 2-е издание. HS Number: HS $\mid 090$ | 12E. ISBN Number: 978-92-1-132505-8. 2013.

2. Закон КР «Об административно-территориальном устройстве КР» от 25 апреля 2008 года №65 / [Электронный ресурс] Режим доступа: http://cbd.minjust.gov.kg/act/view/ru$\mathrm{ru} / 202276 ? \mathrm{cl}=\mathrm{ru}-\mathrm{ru}$

3. Закон КР «О гарантированных государственных социальных стандартах» от 26 мая 2009 г. №170 / [Электронный ресурс] Режим доступа:

http://cbd.minjust.gov.kg/act/view/ru-ru/202576

4. Закон КР «О градостроительстве и архитектуре КР» от 11 января 1994 года № 1372-XII / [Электронный ресурс] Режим доступа: http://cbd.minjust.gov.kg/act/view/ru-ru/716

5. Кенешов Т.С. Генеральные планы городов - залог обеспечения обүектами соцкультбыта населения [Текст] / Т.С. Кенешов // Вестник КГУСТА. - 2017. - Вып. № 4 (58). - c. 16-19.

6. Кенешов Т.С. Современное градостроительное состояние Кыргызстана [Текст] / Т.С. Кенешов // Вестник КГУСТА. - 2017. - Вып. № 4 (58). - с. 19-23.

7. Концепция региональной политики на период 2018-2022 годов (Постановление Правительства Кыргызской Республики от 31 марта 2017 года №194 «Об утверждении Концепции региональной политики Кыргызской Республики на период 2018-2022 годов») / [Электронный ресурс] Режим доступа: http://cbd.minjust.gov.kg/act/view/ru-ru/99907

8. ПРОГРАММА Правительства Кыргызской Республики по разработке генеральных планов населенных пунктов Кыргызской Республики на 2018-2025 годы, от 17 августа 2017 года № 490 / [Электронный ресурс] Режим доступа:

http://cbd.minjust.gov.kg/act/view/ru-ru/100223

9. http://www.stat.kg/ru/statistics/download/operational/825/ 